\title{
Understanding households' livelihood choices, wealth, and poverty in Accra, Ghana
}

\section{Ernest Abraham and Adrienne Martin}

\section{Introduction} poor. need to explore multiple dimensions of poverty.

\begin{abstract}
This article reports on a study that aimed to deepen understanding of the factors which influence livelihood choices, and perceptions of wealth and poverty, in Accra, Ghana. Focus group discussions and household surveys were held in ten selected communities. Although parents are able to influence their households' livelihood choices, the prevailing socioeconomic circumstances are more likely to determine what household members are likely to do. Perceptions of wealth and poverty are influenced by factors both internal and external to households, indicating the complexity and variety of interrelated assets which the poor depend on for their livelihoods.
\end{abstract}

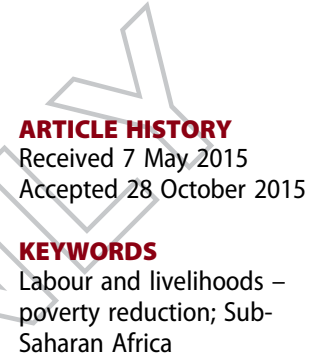

poverty reduction; Sub-

Saharan Africa

\begin{abstract}
"A livelihood comprises the capabilities, assets (including both material and social resources) and activities required for a means of living. A livelihood is sustainable when it can cope with and recover from stresses and shocks and maintain or enhance its capabilities and assets both now and in the future while not undermining the natural resource base." (Carney 1998, 4)
\end{abstract}

Livelihoods suggest that people have the ability to do something with the material and nonmaterial resources available to them. People's assets are conceptualised by five different components: human, physical, social, natural, and financial (DFID 1999). The existing institutional, policy, and organisational framework determines how people are able to acquire these assets and convert them from one form to another. The occurrence of this process enables people to achieve their expected livelihood outcome of improved income, good health, food security, access to water and sanitation, among others, which together lead to improved wealth status and poverty reduction. Thus, some aspects of both wealth and poverty are outcomes of livelihood choices. There are backward linkages in which livelihood situations may trigger particular policy interventions to influence access to particular assets. Though wealth usually constitutes households' desired state, if people are unable to achieve this state or their livelihood outcomes (wealth), they may become

In an attempt to explain the meaning of poverty, Chambers (2002) considered it from four different perspectives; first, income-poverty or its common proxy, consumption-poverty. Second, material lack or want. The third perspective is capability deprivation, referring to what one can or cannot do or be. The fourth perspective is more broadly a multi-dimensional view of deprivation, with material lack or want as only one of several mutually reinforcing dimensions. Therefore, this paper emphasises the

The Chronic Poverty Research Centre (CPRC) suggested another categorisation of the poor, mainly based on the duration of their poverty: occasionally poor, cyclically poor, usually poor, and always poor (CPRC 2004-2005). Poverty also manifests in the form of deprivations located in specific local 
contexts, including insecurity, violence, vulnerability, social and political exclusion, and lack of dignity and basic rights (Kozel and Parker 2003). Evidence suggests that it is a misrepresentation to define poverty only in statistical terms (Hill and Adrangi 1999; Kozel and Parker 2003). Income alone is an inferior indicator of consumer quality of life or satisfaction (Besley and Burgess 2003).

In Ghana, well-being and poverty vary between rural and urban areas and between men, women, young adults, and children. Whereas the rural poor identify issues such as food insecurity, inability to have children, disability, and ownership of property, urban dwellers emphasise lack of employment, the unavailability and inadequacy of social services, lack of skills training, housing, and capital, among others. These are perceived to be linked to poverty and well-being levels (Nkum and Ghatey 2000). In 2007 the percentage of the population below the poverty line in Ghana was estimated at $28.5 \%$ (CIA 2012). Overall incidence of poverty in the Accra Metropolitan Area was officially ranked at $8 \%$ (NDPC 2005).

The conceptual definition of poverty is important for understanding its scope and particular analyses of its dimensions. The above shows that the perception of poverty incorporates both quantitative and qualitative dimensions. Thus, poverty studies can most benefit if statistical assessments are complemented with a qualitative assessment of poverty (Suryanarayana 1996). This is the gap that the paper seeks to contribute to fill. The fluid nature of poverty in populations demands that the designs of efficient poverty response programmes measure the contributions of the poor (Ashworth, Hill, and Walker 1994). Thus, the study's objective was to deepen understanding of the explanations for factors which influence livelihood choices, and perceptions of households' wealth (or well-being), the achievement of positive livelihood outcome, and poverty status.

\section{Study area and methodology}

Ghana (Figure 1) has a population of up to $24,700,000$ inhabitants, with an urban population of $50.9 \%$ (GSS 2013). Accra, the capital city, has a current population of 1,848,614 people (GSS 2013).

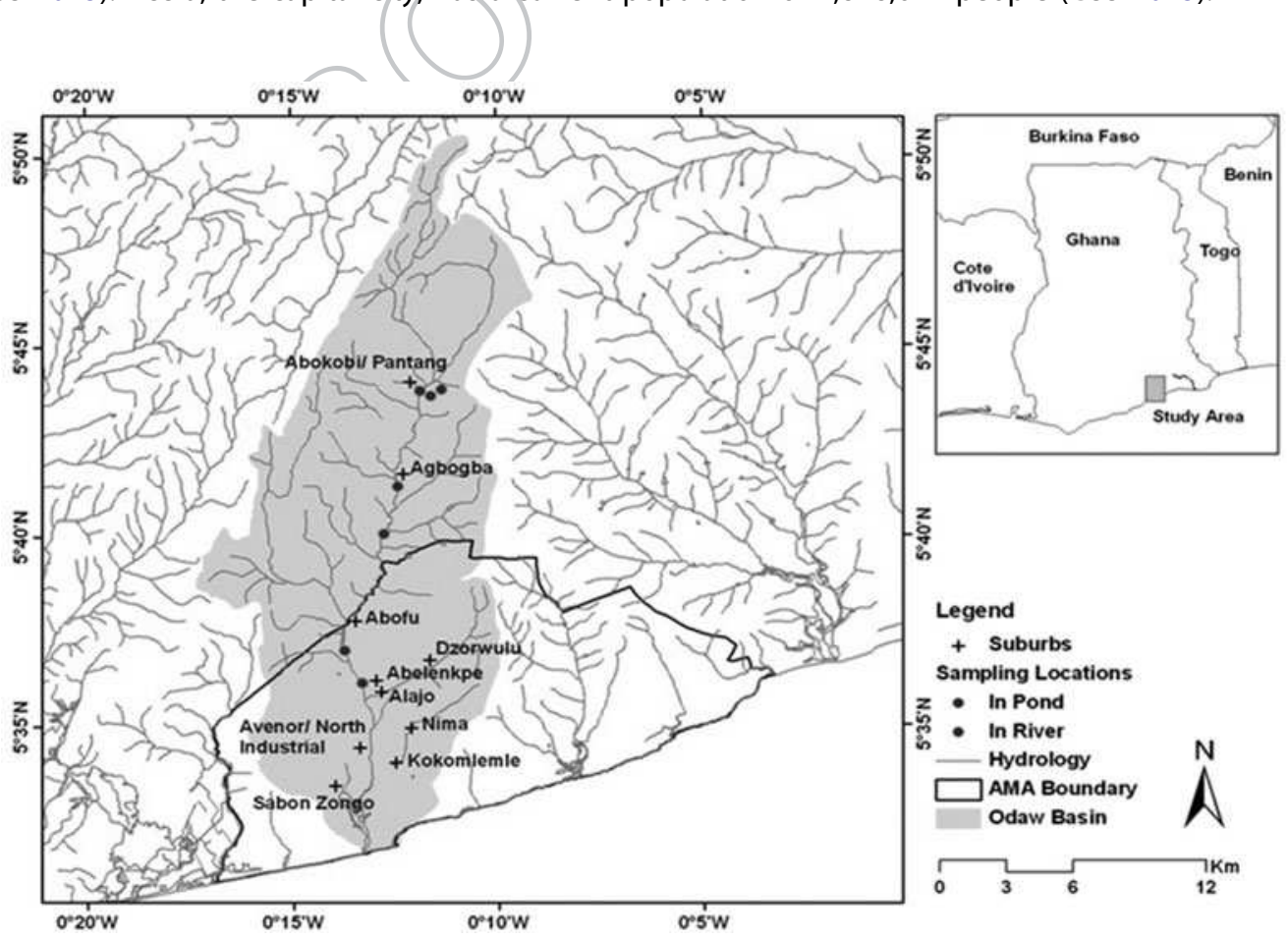

Figure 1. Map of selected communities (suburbs) in the Odaw-Korle River catchment where household interviews were conducted. 


\section{Target population and sample frame}

The population used was all households within the Odaw-Korle River catchment of Accra. The sample frame was ten selected communities in the catchment (Table 1). Since the study was in the OdawKorle River catchment, the researchers began by using a catchment map (CERSGIS 2003) (Figure 1) to provide the initial spatial information on the catchment.

Two important classifications in the city are the income classification of the Accra Metropolitan Assembly (Tables 1 and 2) which groups communities into four main classes (first, second, third, and fourth) (Local Government Bulletin 2002). The second classification used was the 2008 list of property rates which house and other property owners were expected to pay (Table 1). Ten communities indicated in Table 1 were selected to represent different levels of infrastructure provision and environmental conditions: peri-urban - Abokobi-Pantang, Agbogba; high infrastructure provision Abelemkpe, Dzorwulu, Kokomlemle; medium infrastructure provision - Nima, Alajo; and low infrastructure provision - Abofu, North Industrial Area, and Sabon Zongo.

To investigate different perceptions, attitudes, and behaviour, different levels of infrastructure provision were needed as this was expected to present different conditions of access to sanitation and solid waste management; and different experiences in terms of accessing this infrastructure. Different responses to the problems of access were also envisaged to aid in comparative analysis. The perception studies were expected to identify differences in views and beliefs. The Odaw-Korle catchment is also the most urbanised section of Accra, where various issues interact to influence the livelihood decisions of people which may result in wealth or poverty. The philosophy is that differences and similarities in communities may cluster a population. Various dimensions of poverty and what it means to be "trapped" in or "escape" from poverty should also be understood.

The next stage to decide on the sampling frame involved visiting as many communities as possible to ascertain whether the classification provided by the city was reasonable for such a study. The visit was also used to ascertain whether actual conditions on the ground reflected the city classification. This was important because some of the information on the city classification dated from 2002.

A list of the communities in the city was compiled. There were approximately 173 communities identified in the city per the authority's classifications. Approximately 47 of these communities were within the catchment, based on the researchers' knowledge of the city and aided by the catchment map. Approximately 17 were adjacent to the river or have indirect influence within

Table 1. Classification of selected communities in Accra based on average annual per capita income and property rates.

\begin{tabular}{|c|c|c|c|c|c|c|c|}
\hline \multirow{2}{*}{ Selected communities } & \multirow{2}{*}{$\begin{array}{c}\text { Population (Year } \\
\text { 2000) }\end{array}$} & \multirow{2}{*}{$\begin{array}{c}\text { Communities classified by AMA } \\
\text { by income }{ }^{a}\end{array}$} & \multicolumn{5}{|c|}{$\begin{array}{c}2008 \text { imposition of property rates } \\
\text { (Ghana cedi) }{ }^{\mathrm{a}, \mathrm{b}}\end{array}$} \\
\hline & & & $\begin{array}{ll}\mathrm{A} & 1 \mathrm{~B}\end{array}$ & $2 \mathrm{~A}$ & $2 B$ & $3 \mathrm{~A}$ & $3 B$ \\
\hline
\end{tabular}

1 Abokobi/ Pantang

2 Agbogba

3 Abelemkpe

4 Dzorwulu

Kokomlemle

$-$

Nima

Alajo

-

Abofu

$$
\begin{array}{r}
7563 \\
9517 \\
27,616 \\
69,044 \\
23,439 \\
33,352
\end{array}
$$

North industrial area

(Avenor area)

X

[x]

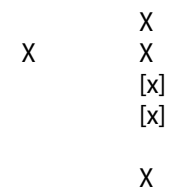

${ }^{a}$ Figures quoted in Ghana cedi are minimum values per house or property: $1 A=50 ; 1 B=30 ; 2 A=25 ; 2 B=20 ; 3 A=15 ; 3 B=10 ; 3 C$ $=8$. A dollar was equivalent to $\mathrm{GHC} 1.44$ on 19 August 2010. The property rates were based on infrastructure provision and environmental conditions (Local Government Bulletin 2008).

${ }^{b}$ Property rate classification; $\mathrm{x}$ was assigned by the city classification; $[\mathrm{x}]$ was assigned by the researchers based on existing information.

Source: Accra Metropolitan Assembly list of communities, gazetted in the Local Government Bulletin (2002). www.ghanadistricts. com/districts/?r=1\&_=3\&sa $=3004$. 
Table 2. Average annual per capita income in Accra.

\begin{tabular}{lc}
\hline Class of community & Average annual per capita income (\$) \\
\hline First & 1519 \\
Second & 883 \\
Third & 793 \\
Fourth & 408 \\
\hline Source: AMA website. Accessed 1 December 2015. www.ghanadistricts.com/ \\
\multicolumn{2}{l}{ districts/?r=1\&=3\&sa=3004. }
\end{tabular}

$0.5-1 \mathrm{~km}$. On the basis of the information above, and the proximity to the Odaw-Korle River catchment, the ten communities indicated above were selected to represent different levels of infrastructure provision and environmental conditions. The Odaw-Korle River is a polluted waterway and the catchment has major water and sanitation problems, which are an aspect of wealth and poverty.

A generic set of questions, informed by the research objective and the grounded theory approach to qualitative data analysis, were developed for the focus group discussions (FGDs). A structured questionnaire was also developed for the household survey.

\section{Data collection}

\section{Focus group discussions}

In each of the ten selected communities, the researchers invited individuals to freely participate in the FGDs. The first main issue discussed was around human and social capital and their influence on households' occupational choices: personal choices, parental support and education, financial support and local economic development, occupational and other associations. The second main issue was around perception of wealth and poverty: understanding what people expect from livelihood choices and well-being; environmental decision-making, financial and natural assets, physical assets, behaviour and health, income-generating opportunity and lack of financial assets, physical assets, and anti-social behaviour.

Four separate FGDs were held in each of the ten selected communities, except Agbogba where only two were organised. The four groups were a mixed group (01), a men's group (02), a women's group (03), and a young adults' group (04) (comprising males and females). The men and women's FGDs were for people aged 36 and above, whereas the young adults group included ages 18 to 35. A total of 38 FGDs were carried out, with the four different groups designed to help to receive different shades of views from participants. Overall, 210 people from the ten communities were involved in the FGDs.

The study of perceptions of wealth and poverty was done to collate views on a cross-section of the population and not necessarily in connection with any specific occupational group that would warrant people with experience in relation to the research questions. Wealth and poverty issues are cross-cutting, therefore including a cross-section of people would enable the researchers to obtain different views for analysis. However, the researchers ensured that participants were drawn from different sections of the communities to reduce bias as much as possible. The FGDs were carried out over a period of about eight months.

Some constructs relating to poverty and attitudes had been developed from group analysis and these were ranked by individual respondents. This is because individual opinions were needed for analysis and to allow for comparison with some of the findings from the focus group analysis. The choice of quantitative method, structured questionnaire interviews, was appropriate because it enabled the investigation to realise the needed data in line with the objective. The questionnaire contained some indicators of poverty categorised into personal well-being, psychological or mental state, access to water and sanitation, health and personal hygiene status, access to jobs, and income, among others. Participants ranked the indicators on a three-point Likert scale, where 1, 2, and 3 represented very important, important, and less important respectively. 


\section{Sample size and household interview}

Structured questionnaires informed by key issues emerging from the FGDs were designed for the household survey. Household interviews with questionnaires made it possible to test some of the households' opinions (McGiverns 2006). Multistage stratified cluster sampling employing disproportionate allocation of samples to each community (cluster) was selected as the sampling procedure. A total of 443 households were sampled and interviewed (Table 3). Respondents were above 18 years of age, the point where one is considered to be a young adult. The questionnaires were administered systematically in each community to reduce bias.

\section{Analysing qualitative data from the field}

In line with the grounded theory approach (Strauss 1987; Morse 2006; Dunne 2011), and starting with one community, key issues from the FGDs; notes were noted and marked. The marked texts were transferred to a table which had three sections; an identification label of the statement which allows it to be traced back to the respective FGD notes and a section for codes generated from the key points (Table 4). The codes could be words or phrases. During the second level of analysis, similar codes were synthesised together as ideas and the ideas also synthesised together at the third level of analysis into themes. The codes, ideas, and themes were compared with the next set of key points from other FGDs from the communities, common ones were noted, and new ones were created, until all notes were analysed (Table 4). Ideas from Table 4:

- Financial position and inability to cater for household basic needs (Pc1, Pm4, Pm5, Pc3; Pm1, Pm2, Py5, Py6, Py7, Py1)

- Nature of dwelling unit (Pm3, Pw1, Pw3, Py4)

- Lack of access to employment and other income-generating activities (Pw4, Py1, Py8, Py1)

Themes:

- Financial resources

- Occupational opportunities

\section{Quantitative analysis of household questionnaires}

All questionnaires were cross-checked and when the investigators were satisfied that due process had been followed, the data were coded and input into an excel spreadsheet. At this stage, the data were verified to be certain that the collected data had been recorded. The data were then transferred into a SPSS version 16 database. Here quality checks were repeated. Frequencies were mainly generated (McGiverns 2006).

Table 3. Sampling allocation for household interviews.

\begin{tabular}{lcc}
\hline Community & Number of households in community & Disproportionate allocation \\
\hline Abokobi/Pantang & 505 & 40 \\
Agbogba & 1517 & 42 \\
Abelemkpe & 1467 & 39 \\
Dzorwulu & 1940 & 40 \\
Kokomlemle & 5839 & 43 \\
Nima & 15,050 & 70 \\
Alajo & 4835 & 42 \\
Abofu & 2968 & 44 \\
North Industrial & 1579 & 40 \\
Sabon Zongo & 4156 & 43 \\
Total & 39,856 & 443 \\
\hline
\end{tabular}

Source: Accra Metropolitan Assembly list of communities. 
Table 4. Analysis of FGDs from Abokobi-Pantang: perception of poverty.

\begin{tabular}{lll}
\hline ID & \multicolumn{1}{c}{ Key } & \multicolumn{1}{c}{ Code } \\
\hline Pc1 & Unable to educate children & Low financial position \\
Pc2 & Farm to provide for household & Relies on local opportunities \\
Pc3 & Low education; unemployment & Low education, inability to afford education of \\
& & children \\
Pm1 & Cannot take care of himself and children & Inability to cater for household \\
Pm2 & No money to buy food or clothes & Inability to take care of households \\
Pm3 & Lacks shelter & Lack of shelter \\
Pm4 & Unable to move due to lack of money and so he/she is always locked up in & Low financial position \\
& thoughts/thinking & \\
Pm5 & Unable to acquire health insurance & Low financial position \\
Pw1 & The shelter shows & Nature of dwelling unit \\
Pw2 & Where the children are shows & Inability to cater for household \\
Pw3 & Live in thatch houses & Nature of dwelling unit \\
Pw4 & Indulge in small-scale stone quarry to make money \\
Pw5 & Someone may be rich but situation can shift him/her into poverty & Engage in low income jobs \\
Py1 & No job so struggles & Unexpected poverty \\
Py2 & Financial difficulty & Lack of a job, inability to cater for household \\
Py3 & Just about half of basic needs, struggle to feed family, borrows to feed & Lack financial capital \\
Py4 & Poor shelter & Inability to cater for household \\
Py5 & Has problem with living & Nature of dwelling unit \\
Py6 & Has to assist someone before getting something to feed & Inability to cater for household \\
Py7 & Difficult to feed, has no support & Inability to cater for household \\
Py8 & Loss of job due to political changes & Inability to cater for household \\
\hline
\end{tabular}

$\mathrm{C}=$ mixed FGD (01); $\mathrm{M}=$ men's FGD (02); $\mathrm{W}=$ women's FGD (03); $Y=$ young adult FGD (04); $\mathrm{P}$ means key point. Source: Field data 2010.

\section{Results and discussion}

The results of the qualitative and quantitative data analyses are presented below. The discussion presents household members' constructs of livelihood choices and the factors which underpin them along the line of the issues discussed in the methodology. In the discussion of results, the following are used: $\mathrm{P}$ - peri-urban community, $\mathrm{H}$ - high infrastructure community, $\mathrm{M}$ - medium infrastructure community; and L - low infrastructure community. Themes and ideas from focus group discussions are indicated where relevant.

\section{Human and social capital and their influence on households' livelihood choices}

According to the sustainable livelihoods framework (DFID 1999), a study into people's livelihoods encourages an investigation of different aspects of human and social capital which households draw on in decisions affecting their occupations and activities. Different dimensions of human and social capital are discussed below.

\section{Personal choices, parental support and education}

The importance of innate abilities and personal choices (theme) in relation to occupations was distilled from focus group discussions in all four levels of infrastructure provision. According to local perceptions, individuals' natural abilities influence their interests and choices for specific occupations. "Someone going to school says that I am perfect in this and that, so that is what I will do" (01, P). The young adults' focus group $(\mathrm{H})$ discussions also indicated that occupational choices are determined by the personal talents and preferences of individuals (idea).

The lack of opportunities in the formal employment sector compels households to consider other alternatives in the informal sector. In such circumstances, some household members, both young and old, set up small businesses to earn income for their households. This also enables people to develop their business and entrepreneurial skills. In any particular community, some economic activities are common and these may also influence the informal activities that people do, especially if there is high 
demand for the products and services of such occupations. This is common in medium infrastructure communities (car washing, informal laundry services, hairdressing, food vending, water vending, hand craft and art work production and vending, pure water vending [sachet water], batik tie and dye cloth production, and trading, among others), but has wide application in the entire city. It is also an avenue for people to make quick returns on their investments. In circumstances where people cannot access such local opportunities, they have to look outside the community.

In all four levels of infrastructure provision, a second theme generated from the focus groups was parental support and influence. Any support from parents depends on their resource base, experiences, and ambitions for their children and the norms within their community. This support is also grounded on the understanding that children, youth, or young adults will cooperate with their parents or guardians. Parents may discourage their children from doing anything apart from what the parents consider as good for them. "In some households the parents may be in a certain job and they will influence their children's jobs" $(01, \mathrm{H})$.

In this context, young men and women work closely with their parents and some are influenced to take after their parents' occupations. "There is a practice in this community where the young women work with their mothers and most of the time they end up doing similar occupations" $(01, \mathrm{M})$. Therefore personal talents and aspirations have to be pursued with some level of determination if they conflict with parental ambitions. Often, individuals may fail to take up the parent's job for good reasons such as the low income of such occupations or the extent of perceived risks. Young adults are also under peer and community influence. Depending on what a group of young adults is pursuing and what is considered in a particular community as important or fashionable, the young adults may pursue similar activities to fulfil the peer expectation or pressure, as was observed in the high infrastructure communities. On the down side, these pressures may result in outcomes such as high rates of teenage pregnancy, which may delay or deny opportunities.

Some occupations are also determined by age and suitable for people with some minimum fitness levels because they involve manual activities (construction, carrying of loaded sacks, etc.). Others are determined by gender (such as female hair dressing - washing and styling). "Age is a factor. The young adults have a lot of energy so they do a lot of manual work. Gender is also a factor. Women young adults only are hair dressers" (01, L).

Discussions indicated that parental support and influence is also related to education and human development (theme). There are opportunities in the informal educational sector for individuals to train as artisans and other entrepreneurs to secure their future. Education creates opportunity for people in the formal sector, and enables people to develop sufficient skills for their respective occupations: "Choice of occupation is influenced by poverty, pressure from parents, peer pressure, role models, [and] level of education which determines the capacity people have built" $(04, \mathrm{H})$. In the low infrastructure communities, interest in education by youth and young adults is so low that it affects opportunities available to them in the communities and the city.

\section{Financial support and local economic development}

340 In all four levels of infrastructure provision, occupational choices are also influenced by the level of available financial support and the coping strategies followed/adopted (theme). The secure financial base of households enables them to access and pay for relevant services. In cases where households depend on low-income occupations and the source of income is seasonal in nature, they will have low and intermittent/income flow. Such households may be financially strained if efforts are not made to move up the economic ladder. This is in line with the classification by Chambers (2002). "Factors which influence occupational choices are financial problems, family conditions and lack of money" $(01, \mathrm{~L})$. This compels households to adopt various measures that will enable them to cope with the economic and financial situation. Therefore it is common that in peri-urban and urban communities, there are some households who are engaged in a productive activity as primary, secondary, or even temporary occupation with the intention of raising capital for further education and skill development to allow them to improve on their income and assets status. In some instances, the 
capital is to invest in a different occupation to improve the income flow of the household: "Some of those in farming do so to save money for business or to train as artisans" (04, P).

Households may also decide to accord some members the opportunity for formal education, while others are made to train as artisans due to limited funds. Households aspire to improve their income flow and therefore choices are sometimes made as a coping strategy (idea). People's daily schedule may therefore include more than one occupation. Occupational choices can also be to enable households to cope with a current situation in preparation for a future opportunity. "There are some, who, for lack of money go into business to save money and then go back to school.

Others also train as artisans and make money and then stop to do businesses" (04, L). Financial resources make investments in formal and informal education possible. A sound financial base offers opportunities to achieve livelihood goals. The situation is quite critical if households are very poor; in that case, members are compelled to take decisive and timely action to improve their income status. Here, members simply have no choice in terms of occupation, it is a matter of survival first and therefore well-being of the family is placed ahead of the individual interest of household members. This was common in the peri-urban areas.

Occupational choices are also determined by urbanisation and its consequences on local economic development (theme). Urbanisation has brought pressure on lands within the city. Consequently, the peri-urban communities offer an opening for households to acquire lands for different development projects. This situation has made land-based productive activities quite unprofitable for community members as there are limited lands for farming and these are threatened with sale in the near future. Given this historical trend and its related threats, opportunities in farming have been constrained, compelling households to expand their capital base by considering alternatives.

\section{Occupational and other associations}

In relation to social networks there were associations which offered various kinds of support to households which were considered poor. There were several occupational-based associations in both the urban and peri-urban communities. Figure 2 presents the involvement of households in occupational associations in the communities, showing low households' involvement.

\section{Perception of wealth (well-being) and poverty}

Wealth status reflects people's desired livelihoods outcome or well-being and if that is not achieved, people fall into poverty.

Physical, financial, and natural assets

An important theme was physical assets (theme). Shelter is very important for both the wealthy and the poor. However, it is expected that the wealthy will either own houses or be able to afford the cost of rent without any difficulty because they have sound financial resources. The nature of the building (material used; high or low quality brick, and cement block) offers some indication of the wealth status of people. Ownership of a house also gives an indication of the wealth status of people. "Wealthy people live in [their] own house, feeding is not a problem, able to pay bills, have tap water and toilet in the house" $(01, \mathrm{~L})$.

A second important theme was financial assets. Employment or income-generating activities provide steady income to wealthy households and because their activities are premised upon good decisions, they are able to apportion financial resources appropriately. Employment is either formal or informal and self-employed or employed by someone else. Another perceived reason for their success is that the wealthy are able to demonstrate a positive attitude towards their occupations and endeavours and therefore are able to make the best out of them. Their decision-making processes in the job sector provide them an opportunity to progress in their chosen occupation. The wealthy have good access to opportunities because they tend to be well positioned to take advantage of circumstances. This enables them to be in a position to be able to afford household-related 


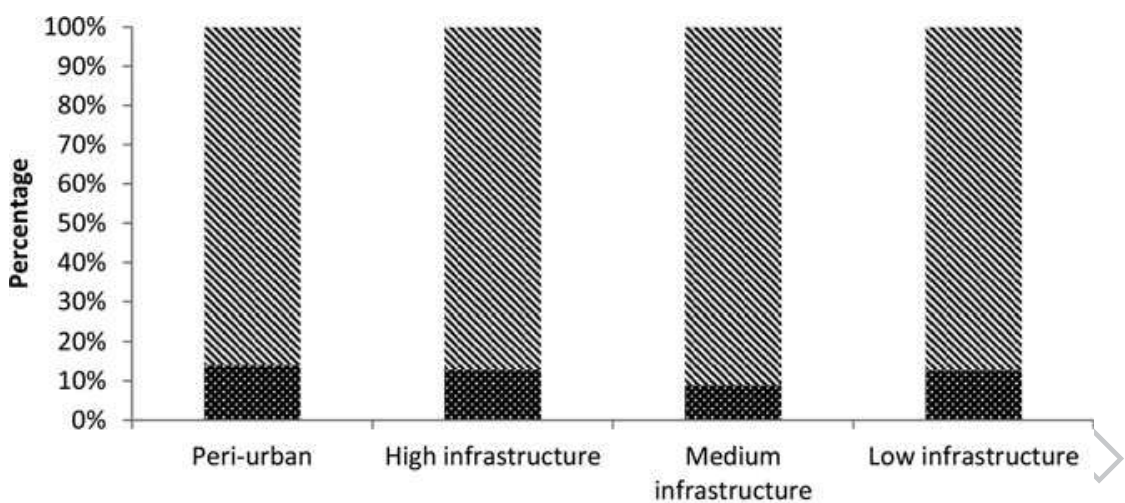

Level of infrastructure provision

Figure 2. Household involvement in occupational association.

expenditure, such as water, sanitation, healthcare, education, clothing, and food. So from the perspective of the communities, poverty interventions should not just provide opportunities but also empower them to take advantage of such opportunities. This is important for interventions aimed at supporting communities.

Financial assets are related to the next theme: natural assets. This emerged from discussions in the peri-urban communities where some people have limited lands for farming, own livestock, and have access to surface water for various activities; in the high infrastructure areas where a few own livestock and the low infrastructure communities where some own livestock and have farms outside the community. The financial position of the wealthy offers them a unique opportunity to invest in land and livestock. These are resources that could be sold or converted into other forms of assets if necessary. This implies that if there are natural assets, during difficult times they can be sold and used for other activities by households.

\section{Environmental decision-making, behaviour, and health}

In the peri-urban, high, and medium infrastructure communities, explanations to wealth included both the material and non-material aspects of human endeavour in line with the view by Kozel and Parker (2003). Wealth manifests in the form of understanding about different facets of life. "Wealth shows in a person's understanding, way of doing things, cleanliness, neatness and how one carries himself/herself about" (01, P). The wealthy are therefore perceived to be cautious in their decisions and actions. This implies that in the perception of communities, wealth does not reflect only in material possessions but in the totality of well-being. This is important for poverty intervention programmes, in that enhancing the skills of individuals to take better decisions is considered as wealth.

The wealthy tend to be conscious of environmental cleanliness and hygiene. They are not expected to fall into behaviour leading to pollution because they can afford the cost of solid and liquid waste disposal and have access to a hygienic toilet. This construct is summarised under the theme personal and environmental decision-making. Therefore wealth, in the understanding of the community, is not just funds in a bank account but high quality behaviour of the household. In addition, they are considered law abiding and are seen as serving as a good example for other community members. Research in different parts of the world, but more importantly in developing countries, favours a more dimensional approach because data reveal that material goods alone may not result in improved living conditions for impoverished citizens (Aturupane, Glow, and Isenman 1994). Poverty can mean more than a lack of what is necessary for material well-being. It 
can also mean the denial or lack of opportunities and choices which are most basic to human development - to enable people to lead a long, healthy, creative life and to enjoy a decent standard of living, freedom, dignity, self-esteem, and the respect of others (UNDP 1997).

Another important theme from discussions in the high and medium infrastructure communities was health and mental status for productivity. This embodies the emotional and the psychological status of the individual which enables people to feel well and relates to a stable mind. The communities believed that health indeed is wealth. A positive health and mental state offers individuals the opportunity to have peace of mind and space to reflect on their actions and decision-making. Interventions aimed at improving the health condition of households in both urban and peri-urban settings are important for enhancing the well-being or wealth status of households. Income alone is an inferior indicator of consumer quality of life or satisfaction (Lane 1991; Easterlin 1995). Dasgupta (1993) agrees and suggests that any measure of consumer well-being should include health and education, because health and education appear to emerge as an embodiment of positive freedoms, while income adds to the enjoyment of this freedom. The role of governments in this is paramount (Besley and Burgess 2003). According to Wharton (1990), insufficiency of human capital such as skills, knowledge, and education, among others, seem to be implicated in truly persistent poverty.

\section{Income-generating opportunities and lack of financial assets}

In the case of poverty, a recurring idea which emerged from the focus groups was a lack of job and income-generating opportunities. Issues of jobs and income are relevant in all categories of the selected communities. The community perception was that the poor struggle to secure employment or even set up their small businesses. Therefore the poor are compelled to depend significantly on local opportunities, if they decide to remain in the communities. This is one important factor trapping poor people in their state. Those who manage to access some opportunities are either exploited (by competition in the system), or their education and skill level do not allow them to rise to formal job positions. Some lack the capacity to negotiate for such occupations. This makes them unproductive in many endeavours. So poverty indeed means more than just what is needed for material well-being (UNDP 1997; Hill and Adrangi 1999). Over $50 \%$ of respondents in all levels of infrastructure provision indicated that lack of a job is either a very important, or an important indicator of poverty (Figure 3). Those who want to apply their entrepreneurial abilities find it difficult to raise the necessary capital to do so.

One dimension of the theme of lack of financial resources (financial assets) was discussed under wealth above. In this context, the poor are engaged in less financially rewarding occupations or other income-generating activities because of limited access to opportunities. The low financial resources pre-suppose that the poor will also find it difficult to invest in savings and other securities for the future. They struggle to afford household-related expenditure (such as food, water, clothing, sanitation, and healthcare) and therefore are unable to pay for goods and services at the household, community, and city levels. "Poverty is inability to afford needs and wants; joblessness;inability to educate children" $(01, \mathrm{P})$. Therefore occupational choices will be aimed at leaving poverty and improving the income and expenditure flow of the household. Figure 4 indicates that over $50 \%$ of respondents in all cases considered the inability to afford three square meals a day as either a very important or an important indicator of poverty, except the peri-urban area where it was only $50 \%$.

In all communities, over $60 \%$ of respondents indicated that low level of access to water and sanitation is either a very important or an important indicator of poverty (Figure 5). Many parts of the city face poor water supply and many depend on sanitation facilities outside of their dwelling units.

One of the elements of access is the ability of households to afford the cost of water and sanitation. Figure 6 indicates that over $60 \%$ of respondents in all the communities indicated that inability to afford the cost of water and sanitation is either a very important or an important indicator of poverty. This agrees with views expressed in the focus group discussions.

Figure 7 shows that the majority (over $60 \%$ ) of respondents in all the communities considered low financial resources as either a very important or an important indicator of poverty. This is in agreement with what was discussed by the focus groups. 


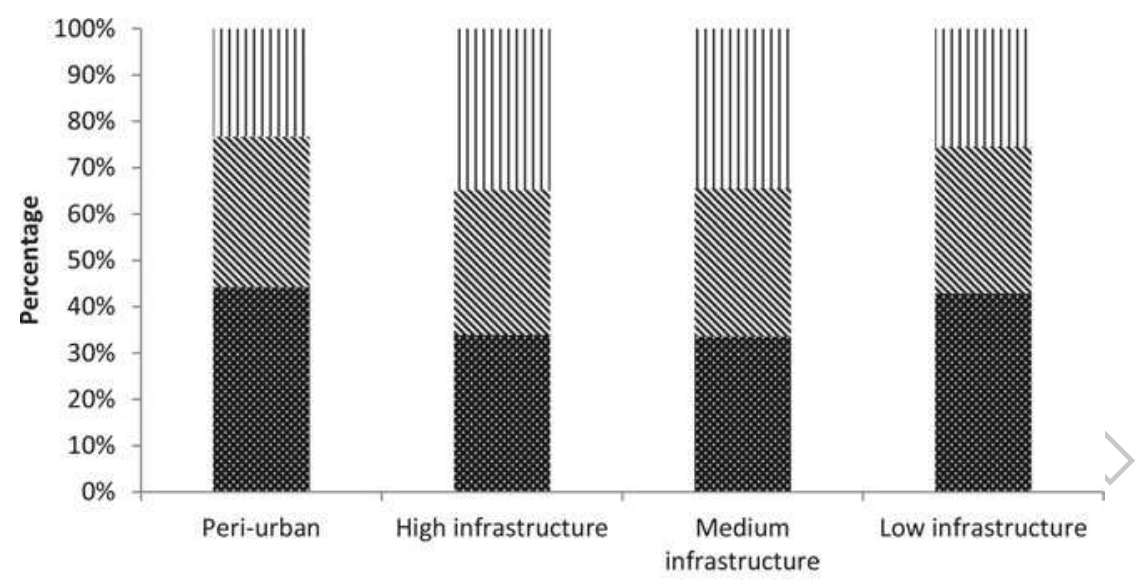

Level of infrastructure provision

Figure 3. Lack of job as indicator of poverty.

Rising cost of living is also trapping the poor in poverty and many are coping by adopting various measures. This compels the poor to make a lot of sacrifices, for example by reducing the frequency and quality of food. It is believed that this will enable the household to shift budgets within the income and expenditure flow. In the worst case scenario, some households may have to seasonally or occasionally beg or rely on family and friends for support in order to get basic items. Poverty can actually be cyclical (CPRC 2004-2005). Therefore, if there are children in the household, they are compelled to engage in small business activities to support the household income flow. Due to the extended family system in Accra and Ghana (Ghana Statistical Service 2013), certain forms of socio-economic support may be extended by family and friends to households living in poverty. The implications of the findings for other regions indicate the need to understand the forms of poverty that prevail in a particular environment and the nature of the coping mechanisms adopted.

\section{Anti-social behaviour}

Another important theme was anti-social attitudes and behaviours. According to informants, the poor often suffer from "poverty of decision-making" and this could trap them in poverty for a long time.

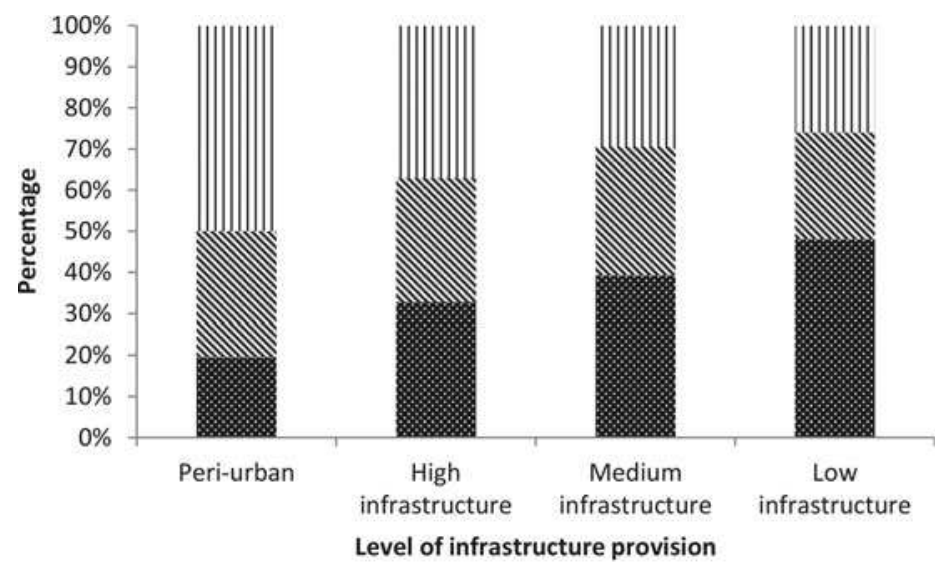

\$ Very important N Important II Less important

Figure 4. Inability to afford three square meals as an indicator of poverty. 


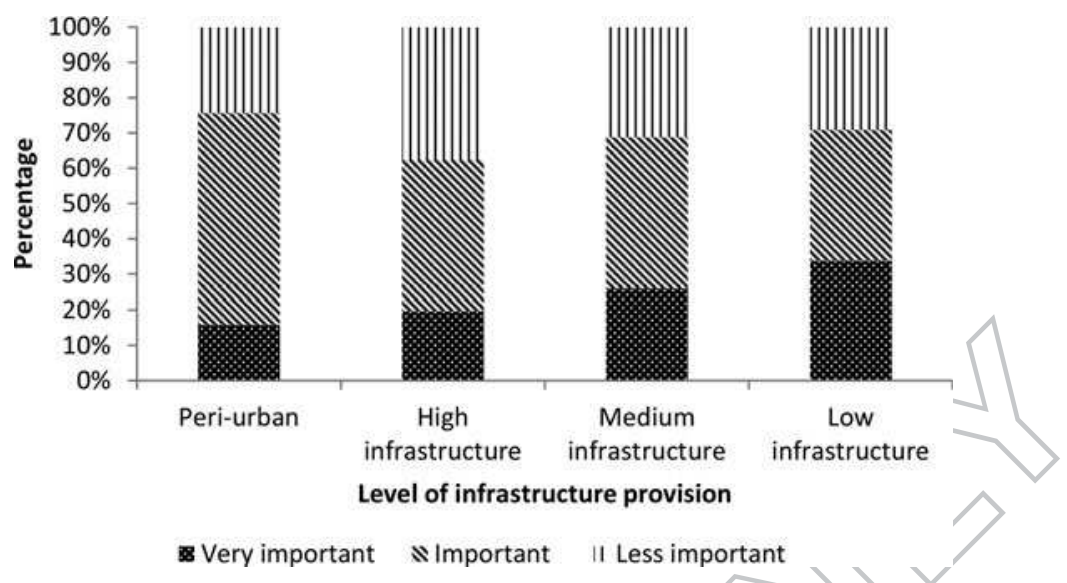

Figure 5. Low level of access to water and sanitation.

Decisions and choices for the household often do not bring the best to them, possibly due to the lack of capacity to take decisions that are likely to engender progress and development (the wealthy are considered to have a good sense of judgment, as discussed above). Therefore their personal demeanour, appearance, and environment demonstrate low living standards.

According to local perceptions, some members of the household are involved in crime and other social vices such as prostitution, armed robbery, theft, alcoholism, substance abuse, lawlessness, among others. The poor are also known to suffer from poor health and mental state for which reasons they tend to be unproductive, as reflected in discussions in the above communities. The poor health may have come from various sources, but may include inability to afford healthcare and the degree of stress and psychological challenges encountered over financial issues. Figure 8 shows that majority of respondents indicated that poor health status is either important or an important indicator of poverty.

The burden of the inability to afford basic needs of households can be a drain on the mental state of the poor, which could affect their health eventually. The majority of respondents (over $70 \%$ ) in all the communities indicated that poor mental state (such as worries, too much thinking about how to provide for self and household) is either a very important or an important indicator of poverty (Figure 9).

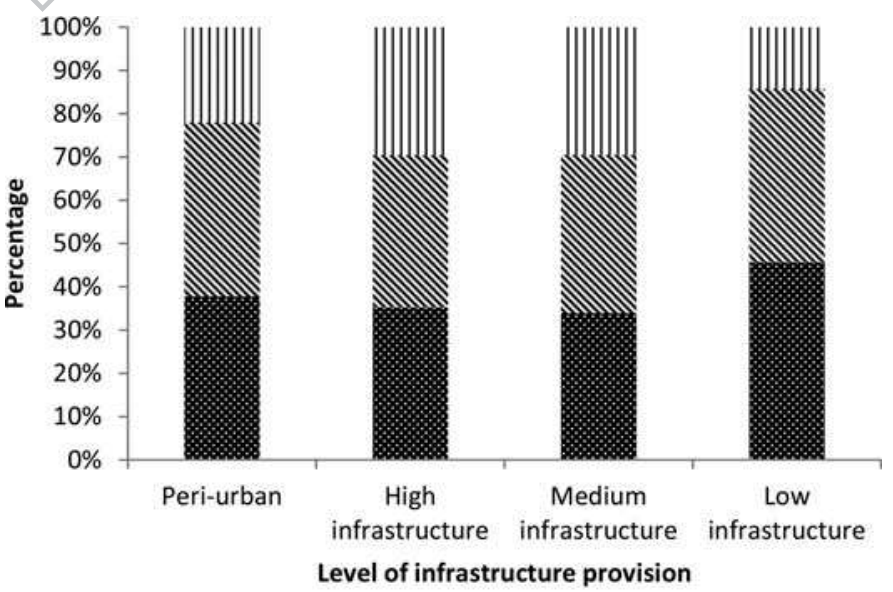

Figure 6. Inability to afford cost of water and sanitation. 


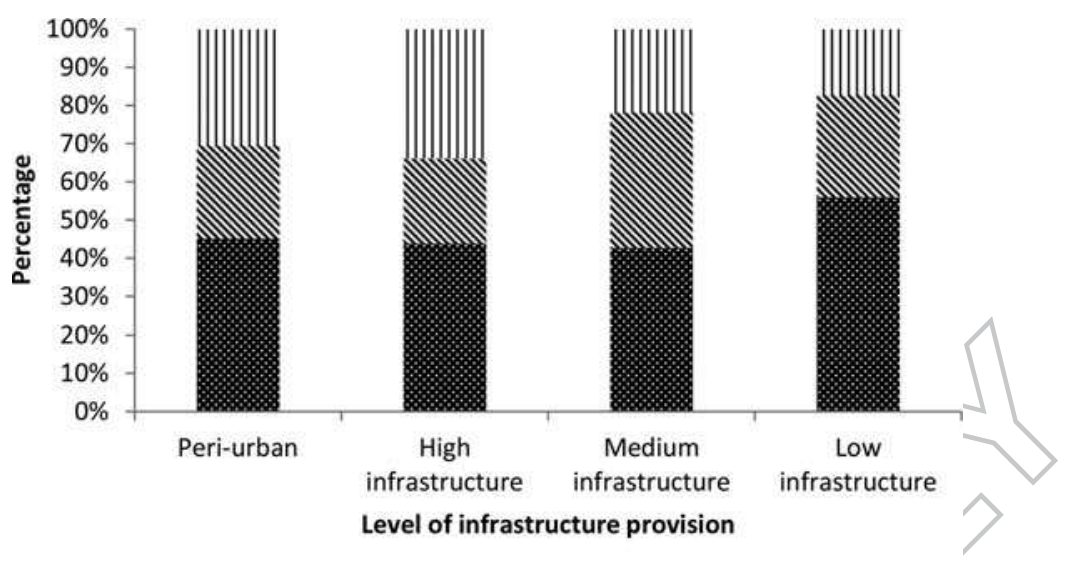

Figure 7. Low financial resources.

\section{Conclusion and recommendations}

The study found that households recognised the role of both internal factors (household circumstances such as ability to afford their needs; the number working; capacity and skills of members, etc.) and external factors (access to jobs, market, support, etc.) which influence what people do or can do. Thus, local and external circumstances and opportunities are more likely to lead households into their livelihoods rather than an active attempt by households to sit together and assign particular occupations to its members as part of its strategy.

People's desired livelihoods outcomes are expressed in their conception of wealth. In doing this, people draw on local knowledge, perceptions, experiences, and circumstances. Wealth or well-being, according to informants, are manifest in a high quality of household assets ownership and not only in financial resources. It encompasses the productivity of the household, social relations, and a highquality attitude to different circumstances of life. Most importantly, the wealthy tend to be exemplary to the society in which they live.

Lack of job opportunities, inability to educate children, low level of access to water and sanitation, high cost of living, and social vices, among others, trap people in poverty. When people fail to achieve their livelihood goals, they may fall into poverty. Consequently, the communities recognised different

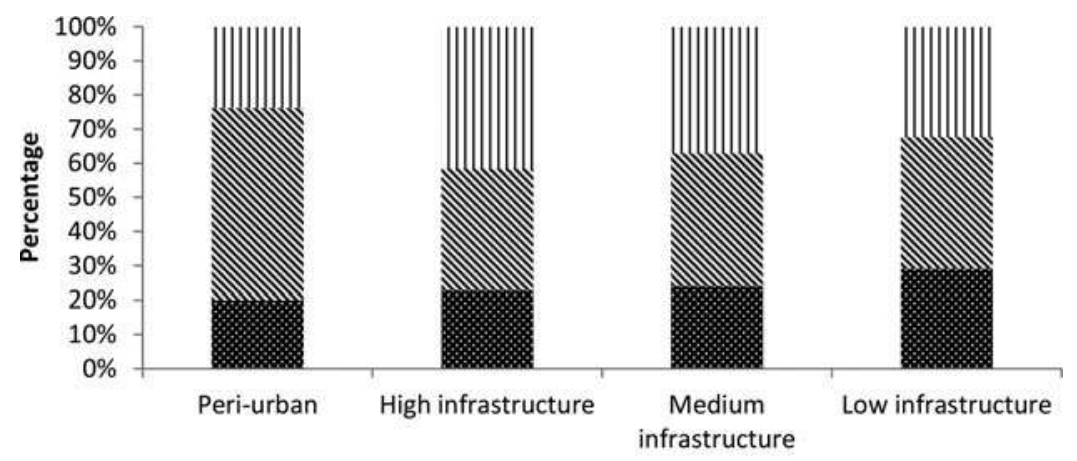

Level of infrastructure provision

Figure 8. Poor health status as an indicator of poverty. 


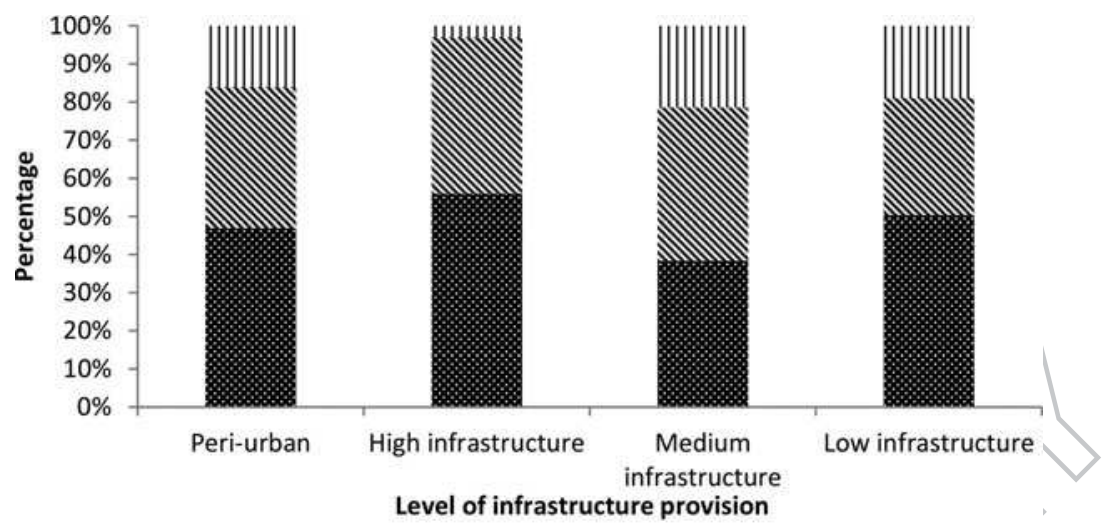

Very important

simportant

II Less important

Figure 9. Poor mental state as an indicator of poverty.

facets of poverty. Poverty is not only associated with lack of financial resources, physical assets, or natural assets, but with poor development of social and human assets resulting in a low quality of life in households (Hill and Adrangi 1999). According to Jodha (1988), a study in Rajasthan carried out poverty identification by the conventional approach using income criterion and qualitative indicators of economic well-being. This study found that households that had become poorer by the income criterion were actually better off by the qualitative measures of economic well-being. Several welfare policy scholars acknowledge the problems created by limiting poverty measurements to only income (Citro and Michael 1995).

The research also found that there are differences in terms of the cycle and type of poverty (CPRC 2004-2005). In terms of the cycle, some households have to engage in begging occasionally or are taken care of by friends and family relations; some struggle to provide for the household. In terms of the type of poverty, there is low household capacity and financial resources; low access to opportunities presented by the market and other external factors; low ownership of certain physical assets at the community level such as social amenities (water and sanitation provision) (Hill and Adrangi 1999); and poverty which has to do with mental state, attitudes, and behaviour to water and environmental pollution.

Those who are trapped in poverty have a series of options. They may improve their effort, or rely on important others, society, or prevailing opportunities in the market to break out of poverty. Support from family and friends, access to temporary jobs in preparation for a future opportunity, improved household income, good health, and improved livelihood skills, among others, help the poor to exit the constraints of poverty. Poverty is multi-dimensional and it is important that efforts to investigate it or intervene in it adopt a holistic and integrated approach (Chambers 2002). A good understanding of the multi-dimensional nature of poverty can improve the success rate of poverty reduction interventions. This is because decisionmakers will have the opportunity to base their interventions on a sound appreciation of the interrelated factors which trap people in poverty or help them to exit poverty. This is especially the case if exploratory studies decide on the indicators with the interest group. The risk of not using a multi-dimensional approach is that interventions may be too targeted as the big picture may be missed.

\section{Acknowledgements}

The researchers are grateful to the Sustainable Water Management Improves Tomorrow Cities Health (SWITCH) Project, the University of Greenwich, UK, and the International Water Management Institute. 


\section{Disclosure statement}

No potential conflict of interest was reported by the authors.

705

710

\section{Notes on contributor}

Ernest Mensah Abraham is a Lecturer at the University of Professional Studies, Accra, Ghana. <emabraham14@gmail. com>

Adrienne M. Martin is Director of Programme Development, University of Greenwich, Natural Resources Institute, UK. <a. m.martin@gre.ac.uk>

\section{References}

Ashworth, K., M. Hill, and R. Walker. 1994. "Patterns of Childhood Poverty: New Challenges for Policy." Journal of Policy Analysis and Management 13 (4): 658-680. doi:10.2307/3325492.

Aturupane, H., P. Glow, and P. Isenman. 1994. "Poverty, Human Development, and Growth: An Emerging Consensus?" American Economic Review 84: 244-249.

Besley, T., and R. Burgess. 2003. "Halving Global Poverty." Journal of Economic Perspectives 17 (3): 3-22. doi:10.1257/ 089533003769204335.

Carney, D. 1998. "Implementing the Sustainable Rural Livelihoods Approach." In Sustainable Rural Livelihoods: What Contributions Can We Make?, edited by D. Carney, 3-23. London: DFID.

CERGIS (Centre for Geographic and Information System). 2003. "Map of Odaw-Korle River Catchment, Accra, Ghana.".

Chambers, R. 2006. "Power, Knowledge and Policy Influence: Reflections on an Experience." In Knowing Poverty: Critical Reflections on Participatory Research and Policy, edited by K. Brock, \& R. McGee, 135-165. London: Routledge.

CIA (Criminal Intelligence Agency). 2012. "The World Fact Book. Africa, Ghana." Accessed September 1, 2014. www.cia. gov/library/publications/the-world-factbook/geos/gh.html.

Citro, C. F., and R. T. Michael. 1995. Measuring Poverty: A New Approach. Washington, DC: National Academy Press.

CPRC (Chronic Poverty Research Centre). 2004-2005. The Chronic Poverty Report. Institute for Development Policy and Management. Manchester: University of Manchester.

Dasgupta, P. 1993. An Inquiry into Well-Being and Destitution. New York: Clarendon Press.

DFID (Department for International Development). 1999. Sustainable Livelihoods Guidance Sheets. London: DFID.

Dunne, C. 2011. "The Place of the Literature Review in Grounded Theory Research." International Journal of Social Research Methodology 14 (2): 111-124. doi:10.1080/13645579.2010.494930.

Easterlin, R. E. 1995. "Will Raising the Incomes of All Increase the Happiness of All?" Journal of Economic Behavior \& Organization 27: 35-47.

GSS (Ghana Statistical Service). 2013. 2010 Population and Housing Census. National Analytical Report. Accra: GSS.

Hill, R. P, and B. Adrangi. 1999. "Global Poverty and the United Nations." Journal of Public Policy \& Marketing 18 (2): $135-$ 146.

Jodha, N. S. 1988. "Poverty Debate in India: A Minority View." Economic and Political Weekly XXIII (45-47): 2421-2428.

Kozel, V., and B. Parker. 2003. "A Profile and Diagnostic of Poverty in Uttar Pradesh." Economic and Political Weekly 38 (4): 385-403.

Lane, R. t. E. 1991. The Market Experience. New York: Cambridge University Press.

Local Government Bulletin. 2002. "Classification of Communities in the Accra Metropolitan Assembly." Unpublished paper. Accra.

McGiverns, Y. 2006. The Practice of Market and Social Research: An Introduction. London: Prentice Hall.

Morse, J. M. 2006. "The Politics of Developing Research Methods." Qualitative Health Research 16 (1): 3-4.

NDPC (National Development Planning Commission). 2005. "Growth and Poverty Reduction Strategy (GPRS II), Ghana." Unpublished paper. Accra.

Nkum and Associates and Ghartey and Associates. 2000. "Poverty Reduction Consultations, NDPC/ GTZ." Unpublished paper. Accra.

Obuobie, E., B. Keraita, G. DansoP. Amoah, O. O. Cofie, L. Raschid-Sally, and P. Drechsel. 2006. Irrigated Vegetable production in Ghana: Characteristics, Benefits, and Risks. Accra: IWMI-RUAF-CPWF.

Strauss, A. L. 1987. Qualitative Analysis for Social Scientists. Cambridge: Cambridge University Press.

Suryanarayana, M. H. 1996. "Poverty Estimates and Indicators: Importance of Data Base." Economic and Political Weekly 31 (35/37): 2487-2497.

Wharton, Jr. C. R. 1990. "Reflections on Poverty." American Journal of Agricultural Economics 72 (5): 1131-1138.

World Bank. 2012. "World Development Indicators." Green Press Initiative. 